\title{
ONGs/Aids, intervenções sociais e novos laços de solidariedade social
}

\author{
Nongovernmental Organizations and AIDS, social \\ intervention, and new ties in social solidarity
}

1 Grupo Pela Vidda. Av. Rio Branco 135, Gr.709, Rio de Janeiro, $R J$ 20040-006, Brasil. 2 Programa de Pós-Graduação em Sociologia e Antropologia Instituto de Filosofia e Ciências Sociais, Universidade Federal do Rio de Janeiro. Largo de São Francisco 1 , sala 420, Rio de Janeiro, $R J$ 20051-070, Brasil.

\begin{abstract}
Starting with a brief contextual analysis of the social scenario in which the AIDS epidemic is occurring in Brazil, the article focuses on the formation of the country's first Nongovernmental Organizations in the struggle against AIDS. There are peculiarities to AIDS NGOs to the extent that they display an ambivalence between the characteristics of a professional institution and a lobbying group, apart from the fact that dealing with sexuality and death breaks down the line between the public and the private spheres. The case in point is the Grupo Pela Vidda (For Life Group) in Rio de Janeiro, which seeks to represent the enhancement of a group of individuals and the principle of universality. The study supports the hypothesis that AIDS NGOs renew ties of social solidarity through the relationships established between various researchers involved in this sector and other NGOs with governmental spheres.
\end{abstract}

Key words AIDS; Non Governmental Organizations; HIV Seropositive

Resumo A partir de uma breve contextualização do cenário social em que surge a epidemia da Aids no Brasil, o artigo situa a formação das primeiras Organizações Não Governamentais de luta contra a Aids no País. Atribuem-se peculiaridades às ONGs/Aids, na medida em que elas apresentam uma ambivalência entre o que caracteriza uma instituição profissionalizada e um grupo de pressão, além de lidar com questões como a sexualidade e a morte, rompendo as fronteiras entre as esferas pública e privada. Tendo como referência o Grupo Pela Vidda/RJ, procura-se apresentar a relação entre a valorização de um grupo de indivíduos e o princípio de universalidade presente na atuação do mesmo. Por fim, apresenta-se a hipótese de que as ONGs/Aids renovam os laços de solidariedade social a partir das relações que estabelecem com as esferas governamentais, os diversos pesquisadores envolvidos com a temática e as outras ONGs.

Palavras-chave Aids; Organizações Não Governamentais; Soropositividade para HIV 
Introdução: um olhar sociológico da epidemia da Aids

A partir de uma breve contextualização do cenário social em que surge a epidemia da Aids no Brasil, este artigo procura situar a formação das primeiras Organizações Não Governamentais de luta contra a Aids - ONGs/Aids. Dois pontos estão subentendidos no processo de formação das ONGs/Aids. O primeiro refere-se à ambivalência entre o que caracteriza uma instituição e um grupo de pressão. O segundo, ao fato da presença de indagações sobre a sexualidade e a morte tornarem flexíveis as fronteiras entre as esferas pública e privada. As ONGs/Aids são percebidas aqui como promotoras de um movimento na sociedade referido por uma ética-prática. Os movimentos éticopráticos, segundo Zarifian (1997), são aqueles que não dissociam o trabalho individual sobre si dos movimentos coletivos, não estão reduzidos a pequenos grupos, mas envolvem um "povo" inteiro devido ao seu potencial de universalidade. A ética apresentada por este autor é uma disposição prática, antes de ser uma maneira reflexiva, enquanto uma visão racional. Ela é construída sobre a apreensão de noções que envolvem a "comunalidade" da existência humana. Neste sentido, a problemática da Aids propicia a criação de novos laços sociais, de uma solidariedade social marcada simultaneamente pelo desconhecido e pela manutenção da existência humana.

A hipótese que orienta este estudo é de que as ONGs/Aids renovam os laços de solidariedade social com base nas relações que estabelecem com as esferas governamentais, os diversos pesquisadores envolvidos com a temática e as outras ONGs. O Grupo Pela Vidda/RJ é apresentado como um grupo que relaciona as demandas individuais ao princípio de universalidade. As reflexões apresentadas fazem parte de uma pesquisa mais ampla em andamento, que possui um caráter exploratório e ainda sem resultados definitivos. As fontes utilizadas foram basicamente bibliográficas acrescidas de alguns documentos, visando à dimensão temporal do processo estudado.

Ao ser caracterizada rapidamente como uma pandemia, a Aids se constitui num fato internacional a partir de um marco médico que data do início dos anos 80 . As respostas à pandemia também ecoam mundialmente, tanto nas relações entre as nações como na troca entre os grupos organizados que começam a se formar. Estes grupos conjugam nos seus países, de acordo com as realidades e os recursos disponíveis, o impacto da notícia inicial baliza- do pela mobilização do movimento gay americano com a necessidade imediata de respostas às situações locais.

No Brasil, o então chamado "câncer gay" ganha as manchetes, inicialmente silenciando muitos, criando cisões e desafetos e, posteriormente, sendo alvo da crítica dos primeiros grupos organizados. A presença das pessoas soropositivas ou com Aids, naquele momento muitos apresentando um quadro de saúde grave, desencadeia um processo de desestruturação social, pois se evidencia a ausência de garantias sociais (manutenção no trabalho, acesso a informações corretas e aos tratamentos etc.) devido a uma nova condição individual e social, e passam a ser reivindicados os direitos das pessoas vivendo com HIV e Aids. A relação entre a Aids e o homoerotismo passa a ser naturalizada gradativamente, devido ao número de casos de Aids entre homens que fazem sexo com outros homens e pela visibilidade que o movimento homossexual propicia à questão, mesmo que de formas diferentes, de acordo com a realidade local. Assim, independente da orientação sexual, as pessoas soropositivas, especialmente os homens, carregam consigo o estigma que já sofriam antes as pessoas com práticas sexuais com outras do mesmo sexo. A conotação negativa destas práticas, associadas ao pecado e ao crime, mais tarde à doença, gera em alguns indivíduos o sentimento de culpa que os leva ao isolamento, à depressão e ao distanciamento da informação e do tratamento. $\mathrm{O}$ que torna mais difíceis as relações sociais, seja com seu/sua parceiro(a), seja com a família ou no ambiente de trabalho.

A política em torno dos direitos sociais e civis desempenha um papel importante na questão da Aids, porque a necessidade de garantias individuais diante de um novo contexto de desigualdades sociais se impõe. Em se tratando da epidemia da Aids, este debate ganha relevância junto à atuação das pessoas atingidas pela epidemia, à organização da sociedade civil e ao avanço da pesquisa médica. $\mathrm{O}$ processo de desenvolvimento da pesquisa médica se impõe como um pano de fundo importante no cenário social marcado pela epidemia da Aids. Funciona como um elemento norteador das relações entre os diferentes atores sociais envolvidos neste cenário. Os recursos tecnológicos da medicina, as descobertas científicas a curto prazo (se comparadas com a história da tuberculose ou da sífilis, por exemplo), a expressão dos grupos organizados na defesa dos interesses das pessoas atingidas e o fato de estes grupos intervirem no andamento das pesquisas médicas geram a reorganização do rit- 
mo do trabalho, da pesquisa e do ativismo, construindo o campo próprio à epidemia. As pesquisas de Pollak (1992) e Broqua (1993) apontam neste sentido. O esforço coletivo na busca da cura da Aids motiva as pessoas soropositivas e com Aids, os médicos, as ONGs/Aids e os representantes das esferas governamentais. Muitas vezes é esta motivação que abala o imobilismo burocrático, seja pelo compromisso cívico de alguns médicos, seja pela pressão social dos grupos organizados, ou ainda, pela presença de pessoas soropositivas também nas esferas governamentais. O que não significa a inexistência de um jogo de interesses entre os diversos atores envolvidos, mas o enigma inicialmente trazido pela Aids gera aproximações entre eles.

Do ponto de vista não governamental, os ativistas das ONGs/Aids realizam uma verdadeira "tradução" da linguagem médica com o intuito de democratizar as informações, mas também de incentivar o cuidado de si. Referindo-se ao caso francês, Broqua (1993) afirma que é por intermédio das associações de luta contra a Aids que são transmitidos os conhecimentos e avanços das pesquisas, fazendo com que a dependência do mundo médico seja relativizada. As ONGs/Aids estabelecem relações formais, institucionais, de parcerias com outros atores sociais e, ao mesmo tempo, são movidas pela avidez das pessoas soropositivas por informações sobre a Aids e por informações sobre o que está se passando consigo mesmas.

No contexto da epidemia da Aids, a atuação das pessoas vivendo com o HIV altera a relação médico-paciente. Entretanto, vale ressaltar que o avanço da pesquisa médica no campo da Aids atualiza os sistemas peritos, para usar a expressão de Giddens (1991), levando os indivíduos a depositarem confiança nos experts no assunto. A participação das pessoas soropositivas e das ONGs/Aids nos protocolos de novos medicamentos é um exemplo, por um lado, dessa confiança, por outro, da criação de uma “ética-prática”, para além dos debates sobre os códigos de ética ou das intervenções nas fases da pesquisa propriamente dita.

As representações sociais geradas pela idéia da morte civil, trazida por Daniel (1989) para retratar a suspensão da cidadania das pessoas vivendo com HIV e Aids, e pela associação direta entre doença e morte faz com que as pessoas evitem ao máximo se identificar como doentes. A própria distinção médica entre soropositividade e Aids (um quadro de doenças decorrentes da infecção pelo HIV) cria conflitos individuais que fazem com que as pessoas ou abram mão dos seus direitos por não se sen- tirem “doentes” ou recorram à aposentadoria se considerando doentes, inaptas, inválidas. Esta distinção pode retardar o início de um tratamento indicado pelo médico, ou mesmo criar resistência a ele por meio de argumentos que rejeitam o número de comprimidos que são necessários por dia, as dificuldades em manter horários, alimentação etc. Evidentemente que em muitos casos os argumentos têm fundamentos e que os efeitos colaterais dos medicamentos podem gerar diversos problemas orgânicos e psicológicos, mas é exatamente este o momento que se quer evitar. $\mathrm{O}$ momento de estar doente. Isto implica não se apresentar publicamente como tal e, conseqüentemente, perder poder de barganha sobre suas necessidades. Do ponto de vista da condição no emprego, essa distinção implica ser soropositivo e estar apto ao trabalho, ou começar a ter problemas em coordenar horários, interferindo na rotina e levando mesmo a um afastamento temporário ou permanente. No que diz respeito à atuação política, a distinção soropositividade/Aids criou um debate polêmico num determinado momento entre as ONGs que se consideravam e eram consideradas como mais "políticas" ou mais "assistencialistas". Um debate importante que muitas vezes aparece fora de foco, criando um embate entre as ONGs e enfraquecendo a negociação do coletivo com as esferas governamentais.

Em resumo, a problemática da Aids pode ser vista como um ícone da modernidade, caracterizada, segundo Giddens (1991), pela separação entre tempo e espaço, pelo desenvolvimento de mecanismos de desencaixe (retirada da atividade social dos contextos localizados, reorganizando as relações sociais em grandes distâncias tempo-espaciais) e pela apropriação reflexiva do conhecimento.

\section{ONGs/Aids e o processo de redemocratização no Brasil}

A história da epidemia da Aids no país surge num momento político marcado pela redemocratização brasileira. Daniel \& Parker (1991:26) contextualizam o surgimento da Aids no Brasil: "A epidemia começou a se desenvolver, precisamente, ao mesmo tempo em que a sociedade brasileira tentava dar seus primeiros passos em direção ao restabelecimento de uma democracia participativa, após duas décadas de regime autoritário".

Para Oliveira (1994), a ditadura militar não conseguiu criar uma sociedade política, no sentido gramsciano, talvez devido ao caráter 
burocrático autoritário do sistema, e o Estado acabou sendo o alvo direto das demandas sociais. É nesse momento que surgem os movimentos sociais. Para o autor, "Do ponto de vista sociológico, os movimentos são a diferenciação e, politicamente, não têm interlocutores. Seu único interlocutor de fato é o Estado" (Oliveira, 1994:8). Por um lado, os partidos políticos, possíveis interlocutores, são postos na clandestinidade, por outro, as demandas sociais surgem ligadas diretamente ao cotidiano da população. Os movimentos sociais constituem a primeira expressão da reconstrução da sociedade civil. A "causa militante" passa a tomar formas mais precisas e mais relacionadas ao cotidiano e aos interesses individuais. Valendo-se dos interesses dos diversos grupos de indivíduos, começa-se a redesenhar uma política global. Estes movimentos, segundo o autor, contribuem para a criação de algumas ONGs e partidos políticos, sendo o mais característico o Partido dos Trabalhadores - PT.

Fala-se de um "pique movimentalista do final da década de 70" (Doimo, 1995:29), sobre o qual as análises destacam "novos sujeitos coletivos" autônomos e independentes que se insurgem contra a ditadura e o Estado. Apesar de gradativamente, como apresenta Doimo (1995) referindo-se ao movimento popular, as disputas internas tomarem o lugar da democracia de base; a "cooptação" de lideranças em vez da independência; e a negociação à da pressão. $\mathrm{O}$ pluralismo e a diversidade trazidos à luz por estes movimentos marcam o cenário social no qual surge a problemática da Aids, que gradativamente constitui um movimento social próprio. Em geral, as ONGs são grupos intermediários entre os movimentos de base e o Estado. No caso da Aids, os grupos organizados se constituem identificando-se como ONG, mas, ao mesmo tempo, possuem uma expressão reivindicativa.

Os estudos de Fernandes \& Carneiro (1991) e de Landim (1993) contribuem na reconstituição do processo de formação das ONGs. Para Landim (1993:33), "O termo ONG começou a ser usado, em meados da década de 80, para identificar um conjunto de entidades que veio se formando a partir dos anos 70, misturando cristianismo e marxismo, militância e profissionalismo, dentro de um quadro de crescente cooperação internacional não governamental, ao qual se ligam."

Os princípios de representação dessas organizações fogem ao caráter clássico, à medida que permitem o surgimento de identidades diferenciadas e se baseando em uma visão relacional. Como assinala Laclau (1991), rompem com a idéia do social como algo fundado. Fernandes \& Carneiro (1991), ao construírem o perfil dos participantes das ONGs definidas num primeiro momento como Organizações Não Governamentais sem fins lucrativos, encontraram pessoas com formação universitária (especialmente nos cursos de filosofia e de sociologia) ou estimuladas a adquiri-las, norteadas por uma causa política, com simpatia partidária pelo PT e com envolvimento religioso, dentre outras características. Segundo Landim (1993), talvez por surgirem no período autoritário e por potencializarem a capacidade de intervenção dos movimentos sociais, as ONGs apareçam como contrapostas ao Estado. No caso das ONGs/Aids esta relação é multifacetada.

O parâmetro de referência das ONGs/Aids são exatamente as ONGs. As ONGs/Aids se aproximam das outras ONGs pela própria conjuntura política e, ao mesmo tempo, estabelecem uma diferenciação fundamentada em uma certa especificidade temática. A dinâminca política de uma ONG/Aids é completamente diferente das outras ONGs, em que a doença e a sexualidade não estão presentes. A sexualidade foi um tema muito marcante nos movimentos gay e feminista no final da década de 70 (associado à liberdade e ao prazer e não à morte), mas em meados da década de 80 estes movimentos possuem uma expressão completamente diferente. A emancipação do desejo não é mais um tema primordial nas suas agendas, sendo mais evidentes discussões legais, como a do aborto ou a da união civil entre homossexuais, ou de inserção no mercado de trabalho. No caso da Aids há evidentemente pontos correlatos, mas especialmente no começo da epidemia as imagens de pecado, crime e doença, que há muito rondaram os movimentos gay e feminista, são revisitadas. Com relação a um movimento de pessoas doentes (hanseníase, câncer, renais crônicos etc.), sua maior expressividade é percebida com a discussão dos portadores de deficiência no processo da Assembléia Nacional Constituinte. A questão da saúde associada ao movimento popular é a que apresenta maior visibilidade, como demonstram as pesquisas de Valla \& Stotz (1993) e Minayo (1986).

Diferente da resposta americana, apoiada inicialmente na comunidade gay, no Brasil a expressão da luta contra a Aids ocorre a partir do surgimento de grupos desenvolvidos com este propósito e que aos poucos consolidam um campo próprio formado pelas ONGs/Aids. Daniel \& Parker (1991) e Bastos (1996) apontam nessa direção. Segundo Daniel \& Parker (1991:27): "Por um lado, um significativo traba- 
lho começou a ser levado adiante por grupos já existentes anteriormente, como a Associação dos Hemofílicos, e pequenos grupos homossexuais, como o Atobá e o GGB, que responderam aos riscos percebidos entre suas diferentes clientelas, envolvendo-se em ações políticas em torno das questões apresentadas pela AIDS, bem como na disseminação de materiais educativos. Por outro lado, um grande número de novos grupos e organizações formaram-se especificamente em resposta à AIDS desde meados de 1985, quando um variado grupo de pessoas - de profissionais de saúde até ativistas políticose membros de organizações homossexuais - reuniram-se em São Paulo para formar o GAPA (Grupo de Apoio à Prevenção à AIDS), uma organização de voluntários destinada a fornecer ajuda básica e serviços de aconselhamento para pessoas com AIDS, bem como para educar e informar o público em geral".

Bastos (1996:9) caracteriza a resposta brasileira à epidemia da Aids, não pela mobilização da comunidade gay - inexpressiva no Brasil, naquela época -, mas pela expressão das ONGs. Considera as ONGs/Aids como parte de "um tipo de grupo muito característico na América Latina dos anos oitenta: as organizações não governamentais, ou ONG". Entretanto, no campo de atuação não governamental a problemática da Aids introduz peculiaridades. As ONGs/Aids, como apresenta Silva (1997:4), "São atores sociais que reconstroem as formas de atuação política, possuem perfis caracterizados pela especificidade da problemática da Aids, constituem, como movimento social, uma trajetória política própria e consolidam seu campo de atuação, gradativamente, expressando-o na realização de dois encontros anuais: o Encontro Nacional de ONGs/Aids e o Encontro Nacional de Pessoas Vivendo com HIV e Aids".

Assim, as ONGs/Aids surgem como resposta aos preconceitos e discriminações gerados nesse contexto e contra uma onda de pânico que marcou o surgimento da epidemia. As lideranças na maioria das vezes não têm um histórico de participação política anterior. São formadas por pessoas atingidas direta ou indiretamente, inicialmente homens gays, e mesmo que haja alguns ex-militantes do movimento homossexual a temática gay não é uma "bandeira" das ONGs/Aids. O caráter de urgência marca o surgimento da epidemia no país. O discurso é de que a Aids é um problema de todos e de que são necessárias respostas imediatas. A trajetória individual entre a descoberta da soropositividade, o adoecimento e a morte também é rápida, seja pelos limites da medicina da época, seja pelo silêncio das pessoas que incorporam a culpa pela sua soropositividade, muitas vezes associada à sua orientação sexual. O tempo individual impulsiona e dimensiona o tempo coletivo no cotidiano das ONGs/ Aids. Exatamente por isso, elas não podem ser entendidas na mesma lógica daquelas que atuam frente às questões ecológicas ou em defesa dos movimentos rurais, por exemplo, até porque, outra de suas peculiaridades, as ONGs/ Aids não atendem a nenhum movimento social, mas criam um movimento próprio e por vezes possuem intersecções quanto ao que as caracteriza como instituições e simultaneamente como movimento.

O movimento social que surge na luta contra a epidemia da Aids no Brasil é concomitante às primeiras discussões governamentais à respeito, ocorridas em 1985. A resposta governamental atende às pressões internas e externas, na medida em que durante os anos 80 grande parte dos países industrializados criam unidades especiais ou coordenações para conceber e gerar programas de luta contra a Aids. O Programa Mundial de Aids da Organização Mundial de Saúde é criado em 1987. A Divisão Nacional de Doenças Sexualmente Transmissíveis/Aids - DNDST/Aids é pensada a partir das ações governamentais iniciadas em 1985, como registram Pedrosa \& Dias (1997:3): “No plano governamental, em 1985, uma portaria ministerial criava a atual Coordenação Nacional de DST e Aids e, em 1986, foram iniciados os trabalhos da então Divisão Nacional de Controle das DST e Aids, do Ministério da Saúde. Integrada por epidemiólogos, sanitaristas e clínicos, o programa logo destacou-se como um dos maiores na estrutura ministerial, mobilizando mais de 30 profissionais".

Paralelamente, o cenário político brasileiro começa a se movimentar em torno da instalação da Assembléia Nacional Constituinte, sendo promulgada a atual Constituição Brasileira em 1988. As ações e os serviços de saúde passam a integrar um Sistema Único de Saúde SUS, organizado sob as diretrizes da descentralização, do atendimento integral e da participação da comunidade.

O perfil epidemiológico da epidemia da Aids no Brasil dimensiona a extensão do problema e das ações em resposta a ele. A população brasileira é de aproximadamente $153 \mathrm{mi}$ lhões de pessoas. Os dados da Coordenação Nacional de DST/Aids, referentes à semana epidemiológica de junho a agosto de 1997 (MS, 1997), registram entre 1980-1997, 116.389 casos de Aids no Brasil, sendo 85.018 casos na região sudeste, 17.081 deles no Rio de Janeiro. Do total, 24.194 casos são de mulheres. O maior 
número de casos encontra-se nas idades entre 13 e 49 anos. Dos casos de Aids notificados, são conhecidos 57.567 (49,5\%) óbitos. Considerando que os registros são somente de casos de Aids, que muitas mortes em decorrência da Aids não são notificadas como tal, seja por desatenção de quem registra, seja pelos casos em que familiares não querem que a Aids apareça como causa mortis, é evidente que os casos notificados estão aquém da realidade e que o alto percentual de óbitos aparece como um indício da precariedade das condições de saúde e da qualidade de vida das pessoas doentes em decorrência da Aids no Brasil. A principal incidência ainda continua sendo na transmissão entre homens, mas assusta o crescimento da epidemia entre as mulheres, conseqüentemente a da transmissão perinatal, acompanhado pela curva ascendente da infecção por uso de drogas injetáveis.

\section{ONGs/Aids e mobilização social}

Se a discriminação, o preconceito e a exclusão são sentidos individualmente, por outro lado, eles são construídos socialmente. A resposta social à epidemia da Aids surge e é impulsionada pelos grupos organizados com este fim. $\mathrm{O}$ ritmo do trabalho em uma ONG/Aids é marcado pelo sentimento de crise e de urgência, mas também de esperança, além do senso de humor, como demonstra Valle (1997). As ONG/ Aids são criadas apostando no seu fim. Depois da cura da Aids sua existência não teria sentido. Neste contexto, embaralham-se as diversas esferas da vida, questionadas constantemente. A democracia refere-se a uma cultura política caracterizada por campos diversos de atuação, diz respeito às ações públicas, mas também às vidas privadas quando a sexualidade e a morte tornam-se tema de debate público.

Uma das características de uma ONG/Aids e que, conseqüentemente, minimiza as fronteiras entre o público e o privado, é o fato de ela ser organizada e mantida pelas pessoas diretamente atingidas pela epidemia, gerando novas formas de atuação política e apresentando a vida privada na criação coletiva. Independente da sorologia dos ativistas, a luta em defesa das pessoas vivendo com HIV e Aids é um princípio que organiza aquele coletivo e que, portanto, deve ser considerado. Na esfera política stricto sensu, as ONGs/Aids criam matrizes de solidariedade que surgem apesar do Estado, além do Estado e com o Estado. Oferecem respostas aos preconceitos e às discriminações quando contribuem para reforçar a auto-estima das pes- soas e se esforçam por manter e/ou criar o reconhecimento dos direitos de cidadania das pessoas que estão vivendo com HIV e Aids.

No esforço de caracterizar o campo bastante complexo das centenas de ONGs/Aids brasileiras, vale registrar a criação do Gapa - Grupo de apoio à prevenção à Aids - em São Paulo, em 1985, seguido de diversos outros Gapas em vários estados brasileiros. A Associação Brasileira Interdisciplinar de Aids (Abia) surge em 1986 com uma proposta de interdisciplinaridade e talvez seja a ONG/Aids mais próxima do modelo das ONGs que trabalham com outras temáticas, até pelo fato de um de seus fundadores e presidente, Herbert de Souza, ter sido o mentor do Ibase - Instituto brasileiro de análises sócio-econômicas. Segundo Pedrosa \& Dias (1997:3): “A ABIA se propunha a tematizar a Aids no contexto maior das políticas públicas, na perspectiva da multidisciplinaridade, sustentando a idéia de que a exclusão e a vulnerabilidade sociais eram facilitadores e potencializadores da infecção pelo HIV e situando a prevenção e assistência numa visão estratégica da democracia."

Ainda em 1986, é criado o Apoio Religioso frente à Aids no Iser - Instituto superior de estudos da religião -, salvo engano o primeiro do gênero. E, é também o Iser que abriga posteriormente um grupo voltado aos trabalhadores do sexo, homens e mulheres, que propicia a criação da Astral - Associação de travestis e liberados, em 1991. Em 1989, é criado o Grupo Pela Vidda/RJ, que como o Gapa, também levará à criação de outros grupos no Brasil. Pedrosa \& Dias (1997:4) falam da criação do Grupo Pela Vidda. "No início de 1989, após recuperarse de uma tuberculose ganglionar e de uma pneumonia por Pneumocystis carinii, Herbert Daniel - como vice-presidente informal da Abia - e um grupo de amigos, fundaram o Grupo pela Valorização, Integração e Dignidade do Doente de Aids (Grupo Pela Vidda). O Pela Vidda insere em sua pauta a necessidade de as pessoas com HIV e Aids terem uma participação ativa e determinante nas políticas públicas para Aids, abandonando a tradicional posição passiva e vitimizada das pessoas com HIV e Aids, predominante em alguns círculos. O Pela Vidda foi a primeira experiência desse gênero na América Latina, ganhando grande visibilidade na $V$ Conferência Internacional de Aids em Montreal (1989) e constituindo-se, junto com a Abia, em um dos fomentadores da criação do Conselho Internacional de Organizações que trabalham com Aids (Icaso)".

Outro tipo de grupo que surgirá em decorrência da epidemia da Aids, especialmente em 
São Paulo, são as “casas de apoio”, que abrigam pessoas com Aids que não têm moradia, que não têm família ou que foram abandonadas pela mesma em decorrência da Aids, além de suprirem a inexistência desse tipo de serviço por parte do Estado. Pedrosa \& Dias (1997) apontam a Casa de Apoio Brenda Lee, criada em atenção aos travestis, como a primeira iniciativa do gênero na América do Sul.

Segundo Silva (1997), as ONGs/Aids vêm construindo uma certa identidade que flutua e por vezes é ambígua, entre o que tem sido caracterizado como ONG e como movimento social. São ONGs quando a menção é feita a cada grupo em separado, mas nos encontros nacionais configura-se, e é denominado como tal, um movimento social peculiar, registrado no Boletim Abia (Abia, 1989:1) como "uma militância radical pela vida”. Para Novaes (1994:8), as ONGs/Aids são "grupos de interesse e pressão que combinam características de entidades de apoio e serviço com características de movimentos sociais substituindo entidades representativas".

As ONGs/Aids brasileiras se reúnem em dois encontros nacionais - o Encontro Nacional de ONGs/Aids e o Encontro Nacional de Pessoas Vivendo com HIV e Aids. Estes Encontros são caracterizados pelo que os ativistas consideram imprescindível e ao mesmo tempo conflituoso em cada uma das organizações: o ativismo e a profissionalização. De um modo geral, pode-se dizer que nos Encontros Nacionais os conceitos de sociabilidade e solidariedade estão estreitamente ligados e quase indissociáveis do conceito de identidade. O emaranhado de identidades cria uma realidade desafiadora, pois exige o exercício da tolerância na convivência entre os indivíduos e os grupos. Os Encontros Nacionais, além das denominadas ONGs/Aids, contam ainda com a participação de representantes de grupos homossexuais e de lésbicas, feministas, grupos que trabalham com crianças na rua, travestis, dentre outros. A participação dos profissionais de saúde é também um dado a ser registrado, seja na exposição de trabalhos ou na convivência dos Encontros.

Os Encontros Nacionais de ONGs/Aids, a partir de 1997, acontecem a cada dois anos. São organizados por uma média de cinco ONGs/Aids eleitas no final do Encontro precedente, quando é definido o estado que sediará o próximo Encontro. Em abril de 1997, em Brasília, estiveram presentes aproximadamente 200 delegados das diversas ONGs/Aids de todo o Brasil. O Encontro Nacional de Pessoas Vivendo com HIV e Aids é anual e difere do En- contro das ONGs. Primeiro, por ser organizado sempre pelas mesmas ONGs e se realizar sempre no Rio de Janeiro. Até 1995, o Grupo Pela Vidda/RJ e a Abia compunham a coordenação do evento, tendo contado com a participação do Grupo Pela Vidda/Niterói neste último ano. A partir de 1996, a organização é dos Grupos Pela Vidda/RJ e Niterói. Apesar de a grande maioria dos participantes ser ativista de uma ONG/Aids, neste evento o apelo pessoal é mais evidente do que no Encontro Nacional de ONGs/Aids em que a preocupação com a pressão política, inclusive nas esferas institucionalizadas, está presente. O Encontro Nacional de Pessoas Vivendo com HIV e Aids inclui no seu programa duas atividades que são do cotidiano do Grupo Pela Vidda - a "sala de conversa" (criada durante uma reunião da comissão organizadora para o III Encontro) e a "tribuna livre”, além das mesas e painéis como o Encontro das ONGs, e, passa a ser identificado pelos próprios participantes, como demonstra Costa Filho (1996), como o "Vivendo", que mais do que uma palavra é um conceito que oferece significado à idéia "Pela Vidda". Em setembro de 1997, o evento contou com a participação de 1.134 pessoas inscritas de todo o Brasil.

\section{Grupo Pela Vidda: valorização individual e perspectiva universalista}

O Grupo Pela Vidda oferece a possibilidade de se observar o entrelaçamento de valores da militância de esquerda presente no período autoritário no Brasil com o princípio do direito a ter direitos, orientado pelo processo de redemocratização e pela expressão dos movimentos sociais e das ONGs nos anos 80. Há um esforço por relacionar uma perspectiva universalista, que orienta a criação do grupo, com a valorização individual que se expressa nas atividades cotidianas e atualiza sua história.

O indício de uma perspectiva universalista aparece no discurso dos ativistas, que afirmam manter determinados princípios ideológicos presentes desde a fundação do grupo, e registrados numa Carta de Princípios escrita na época por Herbert Daniel, como o respeito aos direitos humanos. Os direitos humanos referem-se aos indivíduos em sociedade, logo, à liberdade de expressão, às oportunidades iguais e ao sentido da solidariedade social. Em se tratando das pessoas vivendo com HIV e Aids: à liberdade de falar ou não sobre sua soropositividade, desde que isto não cause danos a outrem; às oportunidades para manter sua melhor qualidade de vida, o exercício da sua fun- 
ção no ambiente de trabalho e o acesso aos cuidados necessários à sua saúde - informações adequadas, tratamentos e medicamentos; e à solidariedade dos indivíduos e dos grupos com os quais se relacionam e que podem contribuir para seu bem-estar físico e mental.

A valorização individual aparece, antes de mais nada, no pressuposto de que todo Grupo Pela Vidda está calcado na criação de espaços de convivência. Os espaços ou reuniões de convivência do Grupo Pela Vidda/RJ compõem uma agenda semanal aberta ao público. Durante as reuniões procura-se criar um pacto de confidencialidade entre os presentes, possibilitando que cada pessoa fale de si mesma sem medo de ser exposta fora do grupo e sem ser censurada pelos presentes. Há uma pessoa que coordena a reunião com o intuito de garantir a expressão de quem fala, de tentar evitar os conselhos de uns para os outros e de estimular a atenção a cada uma das narrativas. A reunião de convivência pode ser, por exemplo, uma "tribuna livre" em que se discute uma questão polêmica referente à Aids (trabalho, eutanásia, sexualidade etc.), ou o "café positivo" em que as pessoas se encontram para ouvir música, conversar, assistir a um vídeo etc. Os espaços de convivência são entendidos como suprindo a necessidade de segurança por parte das pessoas vivendo com HIV e Aids, um espaço onde é possível confiar nos seus pares e onde a confidencialidade deve ser preservada. Parafraseando Giddens (1991:123), “A confiança pessoal torna-se um projeto, a ser "trabalhado" pelas partes envolvidas, e requer a abertura do indivíduo para o outro". A confiança institucionalizada possibilita a exposição da pessoa naquele ambiente e o processo individual de reflexão que proporcionará sua apresentação pública, no momento devido.

A denúncia da morte civil e conseqüentemente da ausência da cidadania das pessoas com HIV e Aids é acompanhada de um processo afirmativo que procura inserir essas pessoas na vida coletiva e deslocar a culpa e a vitimização individualizadas para o processo das relações sociais. Este processo está presente no conceito do "viver" com HIV e Aids, introduzido por Herbert Daniel na criação do primeiro Grupo Pela Vidda. Evidentemente que quem vivencia a soropositividade constrói uma trajetória de vida singular insubstituível, mas a idéia de que todos estamos "vivendo" com HIV e Aids, primeiro protege muitas pessoas que mesmo depois de mais de quinze anos de epidemia não podem expor publicamente sua soropositividade, incita a responsabilidade de todos e todas que vivem num momento histórico datado na qual a epidemia da Aids se faz presente e, no âmbito político, exige do Estado uma prioridade para a questão. Além disso, o grupo, ao criar como princípio a defesa das pessoas vivendo com HIV e Aids, supõe um compromisso individualizado por parte dos ativistas. É a pessoa singular que se encontra implicada.

Os seis Grupos Pela Vidda existentes no Brasil - Rio de Janeiro, Niterói, São Paulo, Curitiba, Vitória e Goiânia - possuem atividades e projetos de intervenção diferentes, de acordo com as demandas locais, mas mantêm e reatualizam os princípios da fundação do primeiro grupo em reuniões periódicas, por meio de suas publicações - Boletim Pela Vidda e Cadernos Pela Vidda - distribuídas em nível nacional e nos Encontros Nacionais de Pessoas Vivendo com HIV e Aids. As pessoas que participam dos Grupos Pela Vidda, independente de serem assalariadas ou não, comungam princípios comuns.

O movimento gerado em resposta à epidemia da Aids, e mais detidamente o Grupo Pela Vidda, pode ser incluído naquilo que Ion (1997:77) denomina como a aparição recente da expressão métiers de l'intervention sociale. $\mathrm{O}$ autor salienta que há um novo modelo de associação e que os "interventores" se vêem numa situação na qual "Eles devem simultaneamente evitar se deixar levar pelos apelos e, ao mesmo tempo, evitar falar em nome deles; é demandado um investimento pessoal especializado ao mesmo tempo em que o anonimato é rigoroso e o turn-over sistematicamente praticado". É evidente a ambivalência proximidade/distância por exemplo no Disque-Aids Pela Vidda, um serviço de informação telefônica. O serviço é mantido por voluntários previamente treinados. Além da informação correta, eles são orientados para ouvir as pessoas com atenção e seriedade. As pessoas que ligam não precisam se identificar, na maioria das vezes perguntam sobre as formas de transmissão do vírus HIV e não raro falam sobre suas práticas sexuais e seus relacionamentos amorosos. No contexto da epidemia da Aids não se trata simplesmente de um trabalho voluntário, mas há um processo de transformação da prática relacional, independente de ela ser voluntária ou profissional. A inserção dos indivíduos nesse métier requer, simultaneamente, engajamento e distanciamento. O exercício do papel profissional supõe a presença da pessoa privada e como afirma Giddens (1991:122), "Embora todas estas conexões sociais possam envolver intimidade emocional, isto não é uma condição da manutenção de confiança pessoal". 
Se a referência ao engajamento dos "militantes" os remetia a uma cosmologia mais ampla, política ou religiosa, a partir da qual dotavam de sentido sua atuação, os "interventores/ativistas", por sua vez, mais do que engajados estão envolvidos nas intervenções sociais voltadas à luta contra a Aids. Nesse sentido, os argumentos de Ion (1997) vêm de encontro à perspectiva da análise deste artigo. O militante deixa de ser o único modelo sobre o qual podese pensar o engajamento no espaço público. $\mathrm{O}$ modelo associativo marca um aspecto contratual e implica engajamentos limitados pelo tempo. Ion (1997) propõe o termo "engajamento distanciado” para desenvolver sua análise. Para o militante, sua pessoa privada só aparece raramente, mas com o "engajamento distanciado” não há mais o sacrifício do privado. A implicação pessoal aparece nitidamente. O autor questiona se não se poderia afirmar que jamais esta implicação teve um efeito tão intenso, apesar de ser sem dúvida controlada. No "engajamento distanciado" é a pessoa singular que se encontra implicada. Sua mobilização não significa uma renúncia de si em nome da "causa", é exatamente ao contrário. Mas, ao mesmo tempo que o engajamento militante pode significar no limite a perda de sua identificação com os papéis do grupo, o engajamento pessoal se arrisca constantemente à tentação do testemunho, quando já não basta a exposição de si. Entretanto, é o engajamento em nome próprio, pela exposição de si, que atribui valor ao engajamento coletivo. Ação e paixão, agir e sofrer se confundem. Para Ion (1997), a oposição entre próximo e distante não é suficiente para avaliar a qualidade do investimento pessoal. Não se trata mais de ser porta voz de ninguém, mas de defender e promover singularidades.

\section{Solidariedade e desigualdades sociais}

As formas de solidariedade social geradas no contexto da epidemia da Aids no Brasil, recolocam em questão a autonomia do Estado e a pressão popular. Como afirma Steffen (1996), em pleno período de sedução neoliberal, a Aids parece reafirmar o engajamento do Estado no setor saúde. Evidentemente que o compromisso estatal é diretamente proporcional ao lugar que a saúde pública ocupa na escala dos valores sociais e políticos. De todo modo, o debate internacional criado pela pandemia da Aids, como assinalado anteriormente, e a pressão das ONGs/Aids conduzem inicialmente à resposta governamental. Por um lado, ainda se- guindo o raciocínio de Steffen (1996), ao assumir as vítimas da Aids, o Estado confirma seu papel tradicional na política social, por outro, a política pública de prevenção se funda sobre uma concepção da responsabilidade individual que não é econômica, mas cultural e política. A Aids exige uma redefinição do setor saúde, da vigilância do sangue e dos investimentos nas pesquisas, dentre outras. Entretanto, o Estado como animador de uma nova gestão do social, criada inclusive em decorrência da Aids, não tem rompido com a tradicional lógica tutelar e contribui para a ambivalência das relações com as ONGs.

No caso do Brasil, grande parte dos projetos desenvolvidos pelas ONGs/Aids contam com o apoio governamental mantido depois do convênio assinado entre o Governo Brasileiro e o Banco Mundial, em março de 1994. Desde então, parte do financiamento é distribuído entre os estados e municípios, as ONGs e os pesquisadores que submetem seus projetos à concorrência pública realizada pela Coordenação Nacional de DST/Aids. A discussão a respeito é bastante complexa, menos pelo apoio financeiro estatal e mais pela maneira como se estabelecem as relações, que não se restringem ao financiamento dos projetos. Há ainda, participações em eventos, participações nas Comissões e Comitês sobre Aids, campanhas publicitárias etc. Por ora, apontam-se algumas dificuldades nas relações entre as esferas governamentais e não governamentais com base no exposto anteriormente, ou seja, as especificidades das ONGs/Aids, o rompimento das fronteiras entre as esferas pública e privada, o alto grau de envolvimento individual (diferente de individualismo) e a grande circularidade dos "quadros políticos" que muitas vezes nem sabem que o são, dada a inexistência de uma atuação política anterior.

Do ponto de vista governamental, há inegavelmente um espaço aberto para o diálogo construído em grande parte pela pressão dos grupos organizados, mas há, também, uma certa solidez instituída que muitas vezes dificulta esse diálogo. Menos do que incitar as iniciativas locais e os projetos aos quais assiste, o Estado em certa medida funciona como animador das iniciativas locais, mas enquadra os projetos nas racionalidades das ações públicas. Muitas vezes nos formulários traduzidos da Organização Mundial de Saúde ou de algum país modelo que pouco ou nada condizem com a realidade brasileira. As prioridades das temáticas, dos investimentos e das ações coincidem com a agenda internacional, importante de ser acompanhada, mas não necessariamente com 
a situação interna, que vem se configurando de forma, aparentemente, mais passiva e menos crítica. A efervescência do social é subsumida nos pressupostos próprios à burocracia estatal. A parceria com as iniciativas da sociedade civil é ainda uma "parceria tutelar", para usar a expressão de Eme (1992), uma contradição em termos.

Outro aspecto muito importante apresentado por Eme (1992), sobre os laços que vão-se formando entre as esferas governamentais e não governamentais diz respeito ao fato de se procurar individualizar os procedimentos em matéria de formação e inserção. A implicação dos indivíduos tende a ser vista como implicação individual, criando o impasse sobre os mecanismos coletivos de mudança. Se a individualização pode ser vantajosa em relação à singularidade dos indivíduos, ela cria um impasse sobre todos os mecanismos coletivos que poderiam ser produtores de laços sociais fora das instituições. Em outras palavras, a gestão individualizada cria o impasse sobre a produção da socialização. Confundem-se, de acordo com os interesses em jogo, as expressões individuais com as relações pessoalizadas, descompromissadas dos laços de solidariedade que em determinado momento fortaleceram as relações entre os diversos atores envolvidos na luta contra a Aids e o caráter coletivizado da mesma.

Com o passar do tempo, o desenvolvimento dos trabalhos locais, o desenvolvimento dos trabalhos das ONGs e suas relações (inclusive com o exterior), poder-se-ia afirmar que há solidariedades locais em torno das ONGs e com outros atores sociais, inclusive governamentais, nos âmbitos estaduais e municipais - dependendo da situação e do processo de descentralização da saúde - e o Estado garante uma solidariedade nacional, que continua sendo importante. Para Eme (1992), a questão é como encontrar novas modalidades de articulação entre o Estado e os grupos, que poderiam inclusive apontar para modos de renovação do Estado de bem-estar. Dito de outro modo, como ampliar o sentido da solidariedade social para além do direito a ter direitos e distingui-lo da compaixão. Apostar nas relações sociais entre atores diferentes, mas que podem ser mais igualitárias e menos tuteladas. Nesse sentido, a problemática da Aids pode contribuir, além do debate sobre a saúde, para discussões sobre as desigualdades e as oportunidades sociais.

Segundo Van Parijs (1996), é preciso refundar a idéia de solidariedade no sentido filosófico e institucional. No primeiro caso, a solidariedade não pode mais ser justificada apenas pela indenização do risco, na lógica do Estado de bem-estar. No sentido institucional, consistiria num conjunto de prestações que exprimam essa solidariedade em garantias acessíveis a todo cidadão, colocando em foco o problema das inserções sociais. A alocação universal, segundo o autor, é o fundamento ético do Estado-providência e para que as garantias individuais sejam consideradas, ela deve ser justa, equitativa e eticamente aceitável. No caso da Aids, não se trata apenas de garantias sobre a realização de um risco, pois a presença das pessoas soropositivas e com Aids denota que ele já se realizou. Mas, como criar mecanismos, além da alocação universal, que garantam a expressão das pessoas soropositivas e com Aids suprimindo o nível de desigualdade engendrado por uma nova condição social. A solidariedade aqui é essencial, mas é fundamental que ela afete todas as esferas da existência e não somente o acesso aos cuidados da saúde. $\mathrm{Nu}$ ma conjuntura marcada, cada vez mais, pela pauperização da epidemia, as exigências éticas não justificam que sejam consideradas as desigualdades unicamente sob o acesso aos cuidados de saúde. As desigualdades de condições no sentido mais amplo, do ponto de vista da seguridade, do emprego e do meio de vida, não são menos importantes. Assim, repetir o discurso da pauperização da epidemia - no âmbito governamental ou não - pode ser uma maneira rápida de banalizar o problema sem uma análise mais detida da associação entre a Aids e a miséria. Para além das participações nos fóruns internacionais, do excelente nível dos pesquisadores, muitas vezes mais reconhecidos no exterior do que no seu próprio país, o caso brasileiro apresenta um desafio fundamental a ser enfrentado: o imaginário social da epidemia é concomitante ao alto grau de desigualdades sociais no país. O acesso aos medicamentos é tão importante quanto à alimentação e à liberdade de expressão, além disso o avanço da pesquisa médica não controlou a terceira epidemia. 


\section{Referências}

ABIA, 1989. A vida em emergência - Rede Brasileira de Solidariedade. Boletim Abia, 9:1.

BASTOS, C., 1996. Respostas sociais à Aids: o movimento internacional e as organizações locais. Trabalho apresentado no IV Congresso Luso-afrobrasileiro de Ciências Sociais, Anais. Rio de Janeiro:Instituto de Filosofia e Ciências Sociais, Universidade Federal do Rio de Janeiro.

BROQUA, C., 1993. Activisme et Sida: l'Association Act up-Paris. Nanterre: DEA d'anthropologie, Université Paris X.

COSTA FILHO, R.B., 1996. Sotaques do Vivendo. Revista Vivendo, pp. 5.

DANIEL, H., 1989. Vida Antes da Morte/Life Before Death. Rio de Janeiro: Jaboti.

DANIEL, H. \& PARKER, R., 1991. Aids - A Terceira Epidemia. São Paulo: Iglu.

DOIMO, A. M., 1995. A Vez e a Voz do Popular: Movimentos Sociais e Participação Política no Brasil Pós-70. Rio de Janeiro: Relume-Dumará/Anpocs.

EME, B., 1992. Les services de proximité: des lieux à inventer. In: Exclusion et solidarité (M.-O. Terrenoire, J. Roan \& D. Picard, orgs.), pp. 178-189, Paris: L'Arche de la fraternité.

FERNANDES, R. C. \& CARNEIRO, L. P., 1991. ONGs Anos 90 - A Opinião dos Dirigentes Brasileiros. Rio de Janeiro: Núcleo de Pesquisa/Iser. Série Textos de Pesquisa, 1.

GIDDENS, A., 1991. As Conseqüências da Modernidade. São Paulo: Unesp.

ION, J., 1997. Interventions sociales, engagements bénévoles et mobilisation des expériences personnelles. In: Engagement Public et Exposition de la Personne (J. Ion \& M. Peroni, orgs.), pp.77-84, Paris: Éditions de l'Aube.

LACLAU, E., 1991. A política e os limites da modernidade. In: Pós-modernismo e Política (H. B. de Hollanda, org.), pp. 127-149. Rio de Janeiro: Rocco.

LANDIM, L., 1993. Para Além do Mercado e do Estado? Filantropia e Cidadania no Brasil. Rio de Janeiro: Núcleo de Pesquisa/Iser.
MINAYO, M.C.S., 1986. A Saúde em Estado de Choque. Rio de Janeiro: Fase/Espaço e Tempo.

MS (Ministério da Saúde), 1997. Semana Epidemiológica 23/97 a 35/97. Boletim Epidemiológico DST/ AIDS, 7: 3

NOVAES, R., 1994. ONGs/Aids - mais perguntas do que respostas, Boletim Pela Vidda, 18:8-9.

OLIVEIRA, F., 1994. Estado, Sociedade, Movimentos Sociais e Políticas Públicas no Limiar do Século $X X I$. Rio de Janeiro: Fase/PIC.

PEDROSA, J. S. \& DIAS, J. L. M., 1997. Sobre Valores e Fatos: A Experiência das ONG que Trabalham com Aids no Brasil. Brasília: Coordenação Nacional de DST e Aids/Ministério da Saúde.

POLLAK, M., 1992. Histoire d'une cause. Autrement, 130:24-39.

SILVA, C. L. C., 1997. ONGs/Aids: organização e/ou movimento? Trabalho apresentado na III Jornada de Pesquisadores do Centro de Filosofia e Ciências Humanas da Universidade Federal do Rio de Janeiro. Rio de Janeiro: Universidade Federal do Rio de Janeiro.

STEFFEN, M., 1996. Solidarité, santé, sida: de nouveaux défis. In: Les solidarités: fondements et défis (Alain et Chantal Euzéby, Org.), pp. 157-179, Paris: Economica.

VALLA, V. V. \& STOTZ, E. N., 1993. Participação Popular, Educação e Saúde: Teoria e Prática. Rio de Janeiro: Relume-Dumará.

VALLE, C. G. O., 1997. Identidades sexuais, humor e experiência no contexto da Aids. Trabalho apresentado na Reunião Anual da Associação Nacional de Pós-Graduação e Pesquisa em Ciências Sociais - Anpocs. Caxambú: Anpocs.

VAN PARIJS, P., 1996. Refonder la Solidarité. Paris: Les éditions du Cerf.

ZARIFIAN, P., 1997. Éloge de la Civilité: Critique du Citoyen Moderne. Paris; Montréal: L’Harmattan. 